\title{
A PFC Fed Asynchronous Generator For Advanced Wind Power Generation Excited By Voltage Source Inverter
}

\author{
Vipul saini ${ }^{1}$, Alka Agarwal $^{2}$, Vinesh $_{\text {Agarwal }}{ }^{3}$ \\ M.Tech. student in Electrical Engineering Department, ITM Bhilwara ${ }^{1}$, \\ Assistant Professor in Electrical Engineering Department, ITM Bhilwara ${ }^{2}$, \\ Assistant Prof essor in Electrical Engineering Department, ITM Bhilwara ${ }^{3}$
}

\begin{abstract}
In this paper shows the simulation results about the reduction of the current peak of PFC converter connected to voltage source converter excited induction generator for wind power generation. This is one of the investigations of new combination of the induction generator for wind power and the power electronic equipments. Induction generator is popularly used for the wind power generation. The disadvantage of it is impossible to generate power at the lower rotor speed than the synchronous speed. To compensate this disadvantage, expensive synchronous generator with the permanent magnets sometimes used. In proposed scheme, the diode rectifier is used to convert the real power from the induction generator to the intermediate dc voltage, while the reactive power necessary to excite the induction generator only is supplied from the voltage source converter (VSC). This means that the rating of the expensive VSC is minimized and total cost of the wind power generation system is decreased compared to the system with synchronous generator. The MATLAB/Simulink is made for the controlling of the voltage source converter and boost $d c / d c$ chopper. By using the duty ratio of the chopper can be controlled and for the generation of pulse width modulated (PWM) firing pulses for the voltage source converter.
\end{abstract}

Index Terms: WECS, Total harmonics distortion, , FFT, SCIG, VSC

\section{Introduction}

The energy which human being need every day comes from resources. Resources are divided into two parts which are named as renewable and non-renewable resources. Non-renewable resources can be used once. The most used non-renewable resources are coal and petroleum. Because of the cost of these resources and the lack of their reserve in the world, human being is forced to look for different sources. Non-renewable resources are also polluting the world and causing global warming problems. Achieving solution to environmental problems that we face today requires long-term potential actions for sustainable development. In this regard, renewable energy resources appear to be the one of the most efficient and effective solutions. Renewable resources can be used repeatedly.

As the title of the project is self explanatory about objectives but here defining objectives again makes it clearer for report. The FFT algorithm is used to analyze the harmonic currents and voltages under steady-state conditions..The proposed system is formulated in MATLAB/SIMULINK software. Following are the main objectives of the project. To study about to reduce the output current of the VSC by using the duty factor control of the PFC converter in the system. To study about reduce the total cost of the entire system. To analyze voltage profile Improvement with Boost converter. To reduce the cost cage induction motor is used instead of expensive synchronous generator. Capacitors are used to compensate the reactive power.

\section{Asynchronous Generator Configurations}

The Asynchronous Generator is a very reliable generator that was originally designed as an electric motor but is used as a generator and tends to be comparatively inexpensive and has some mechanical properties that are useful for wind turbines. There is a very important element that makes the asynchronous generator different from the synchronous, that element being the Cage Rotor. In fact one third of the world's electricity consumption is used for running induction motors driving machinery in factories, pumps, fans, compressors, elevators, and other applications where you need to convert electrical energy to mechanical energy.

Principal of Operation Induction generators and motors produce electrical power when their rotor is rotated faster than the synchronous frequency. For a typical four-pole motor (two pairs of poles on stator) operating on a $60 \mathrm{~Hz}$ electrical grid, synchronous speed is 1800 rotations per minute. Similar four-pole motor operating on a 50 $\mathrm{Hz}$ grid will have synchronous speed equal to $1500 \mathrm{rpm}$. In normal motor operation, stator flux rotation is faster than the rotor rotation. This is initiating stator flux to induce rotor currents, which create rotor flux with magnetic polarity opposite to stator. In this way, rotor is dragged along behind stator flux, by value equal to slip. In generator operation, a prime mover (turbine, engine) drives the rotor above the synchronous speed. 
Stator flux still induces currents in the rotor, but since the opposing rotor flux is now cutting the stator coils, active current is produced in stator coils, and motor is now operating as a generator, and sending power back to the electrical grid. Grid and stand-alone connections: In induction generators the magnetizing flux is established by a capacitor bank connected to the machine in case of stand-alone system and in case of grid connection it draws magnetizing current from the grid. For a grid connected system, frequency and voltage of the machine will be dictated by the electric grid, since it is very small compared to the whole system. For stand-alone systems, frequency and voltage are complex function of machine parameters, capacitance used for excitation, and load value and type.

\section{Grid Connected Induction Generator}

Grid connected induction generators develop their excitation from the Utility grid. The generated power is fed to the supply system when the IG is run above synchronous speed. Machines with cage type rotor feed only through the stator and generally operate at low negative slip. But wound rotor machines can feed power through the stator as well as rotor to the bus over a wide range known as Doubly Fed Induction Machines [2]

\section{Fixed Speed Grid Connected Wind Turbine Generator}

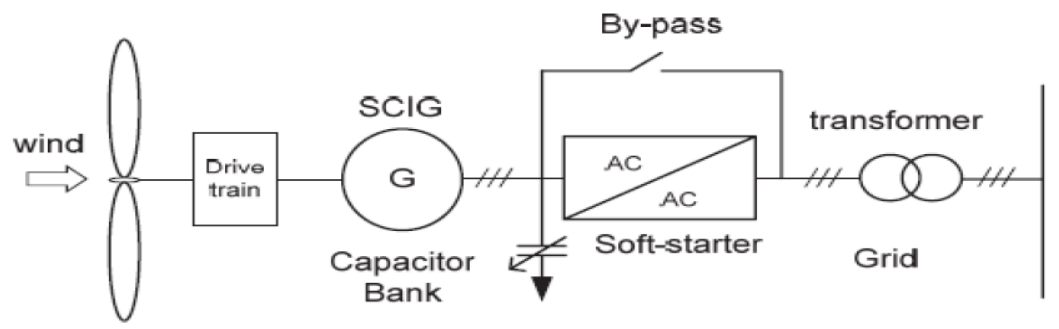

Fig 1.1 Fixed Speed Wind Turbine with Directly Grid Connected Squirrel-Cage Induction Generator The reaction time of these mechanical circuits may lie in the range of tens of milliseconds. As a result, each time a burst of wind hits the turbine, a rapid variation of electrical output power can be observed. These variations in electric power generated not only require a firm power grid to enable stable operation, but also require a wellbuilt mechanical design to absorb high mechanical stress, which leads to expensive mechanical structure, especially at high-rated power.

\section{Variable Speed Wind Turbine Generator}

A way to make more convenient turbines is variable speed turbines. Variable speed turbines have become the most dominating type of the yearly installed wind turbines as they can store some of the power fluctuations due to turbulence by increasing the rotor speed, pitching the rotor blades, these turbines can control the power output at any given wind speed.

Fig. 1.2 shows a variable speed turbine connected to a Squirrel- Cage Induction Generator SCIG. Although these direct-online systems have been built up to $1.5 \mathrm{MW}$, but presence of power inverter causes lots of disadvantages such as:

(a) This power converter, which has to be rated at 1 p.u. of total system power, is expensive.

b) Converter efficiency plays an important role in total system efficiency over the entire operating range.

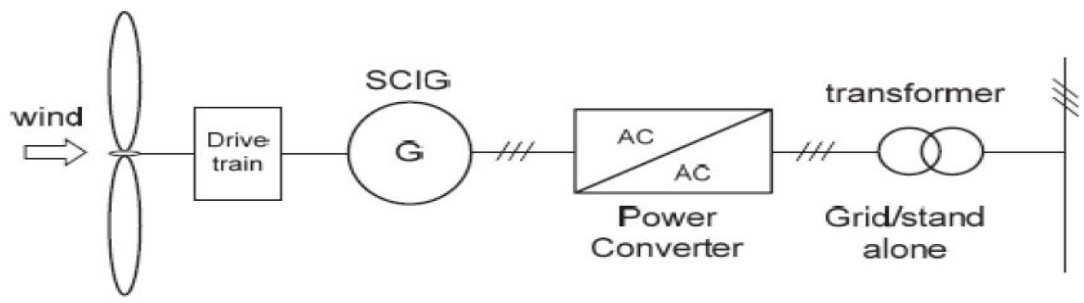

Fig 1.2: Variable Speed Wind Turbine with Squirrel-Cage Induction Generator

\section{Power Electronic Converter Topology}

Power electronics is a rapidly developing technology. Components are getting higher current and voltage ratings, the power losses decrease and the devices become more reliable. The devices are also very easy to control with mega scale power amplification. The prices are still going down pr. kVA and power converters are becoming attractive as a mean to improve the performance of a wind turbine. While the VSI creates a 
relatively well-defined, switched voltage waveform at the terminals of the electrical machine, the CSC produces a switched current waveform. In the case of a VSI, the voltage in the energy storage (the DC bus) is maintained stiff by a large capacitor or a DC source e.g. a battery (voltage source inverter) $\tilde{n}$ while the resulting current is primarily formed by load and speed. In a CSC the opposite is the case, the current in the energy storage (the DC bus) is maintained stiff using a large inductor $\tilde{n}$ while the resulting voltage is primarily formed by load and speed. Thus, VSI and CSI are dual. A diagram of the basic inverter concepts. It must be stressed, that VSI and CSI are quite different concepts.

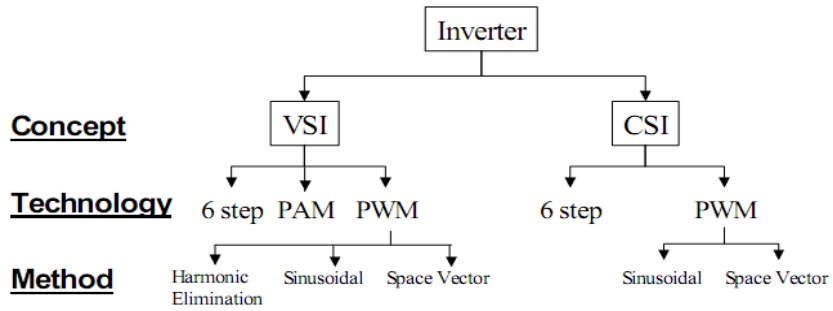

Fig 1.3 Diagram of Basic Inverter Concepts for Adjustable Speed in Wind Turbines.

\section{Unidirectional Power Converter}

A wound rotor synchronous generator requires only a simple diode bridge rectifier for the generator side converter as shown in Fig 1.4 . The diode rectifier is the most common used topology in power electronic applications. For a three-phase system it consists of six diodes. The diode rectifier can only be used in one quadrant, it is simple and it is not possible to control it. It could be used in some applications with a DC-link

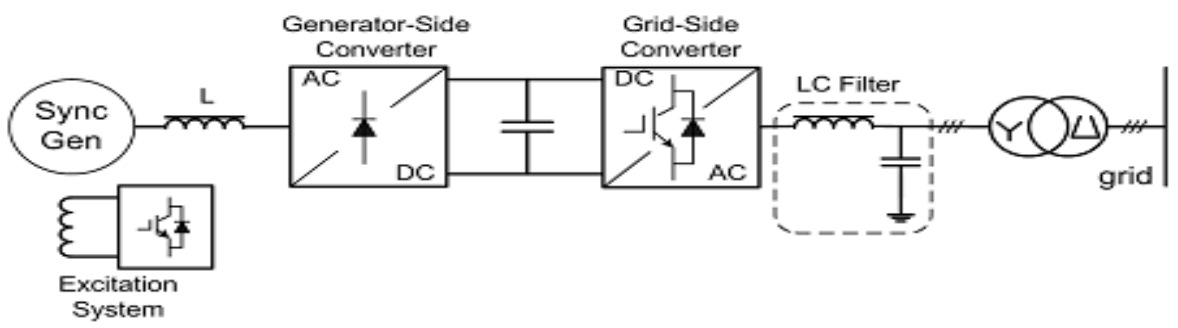

Fig 1.4 Variable Speed Wind Turbine with Synchronous Generator and full-rating Power Converter.

$>$ Proposed Converter

The proposed converter consists of Power Factor Correction Converter (PFCC) and Voltage Source Converter (VSC).

$>$ Power Factor Correction Converter (PFCC)

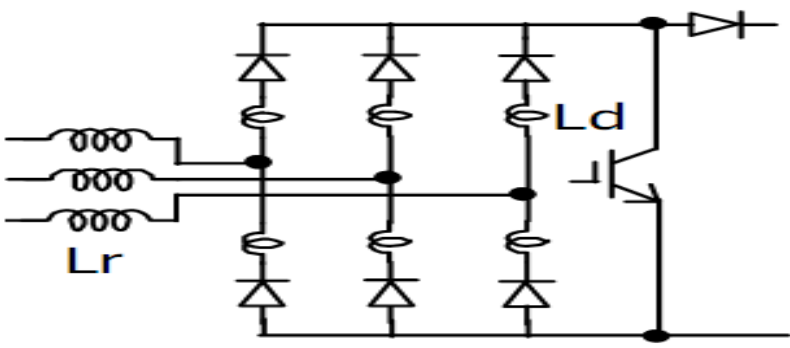

Fig 1.5 PFC Converter with Diode Rectifier and Boost Chopper

In the three phase diode rectifier there is no inductor in series with the diode but for PFC converter there was a inductor to limit the current distortion in ac side. Fig. 3.12 shows the power factor corrected (PFC) converter consists of the diode rectifier and the boost dc/dc chopper. For single phase PFC converter, dc reactor is usually placed between the diode rectifier and the dc switch. In this 3-phase converter, the reactors are placed in series with the diodes and reduce the current distortion in ac side.

\section{Voltage Source Converter (VSC)}

The circuit configuration of Fig. 1.6 shows the voltage sourced converter used for the inverter in proposed system. Pulse width modulation (PWM), using the comparison of the triangular waveform and the sinusoidal waveform, makes it possible to change the output voltage amplitude and frequency easily. The 
fundamental frequency of the output voltage of the inverter is the synchronous frequency of the induction machine. When the wind speed is low and the rotor speed is less than the power system synchronous speed, the inverter generate the lower frequency and makes it possible to generate the electric power from the induction machine since the rotor speed can exceed the synchronous speed.

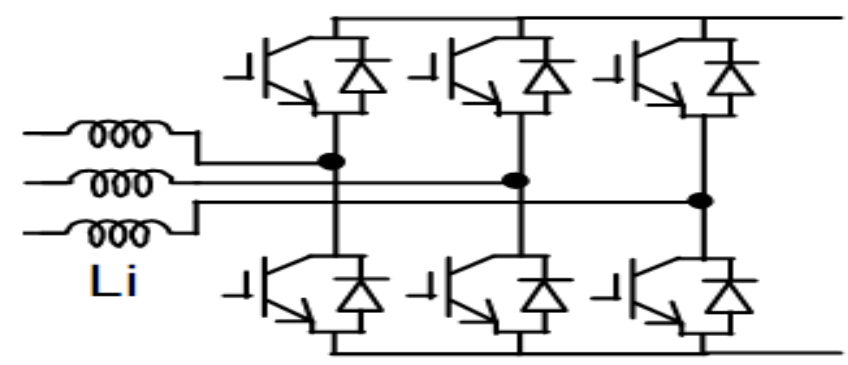

Fig 1.6 Voltage Source Converter.

\section{Pfc Converter Fed Induction Generator}

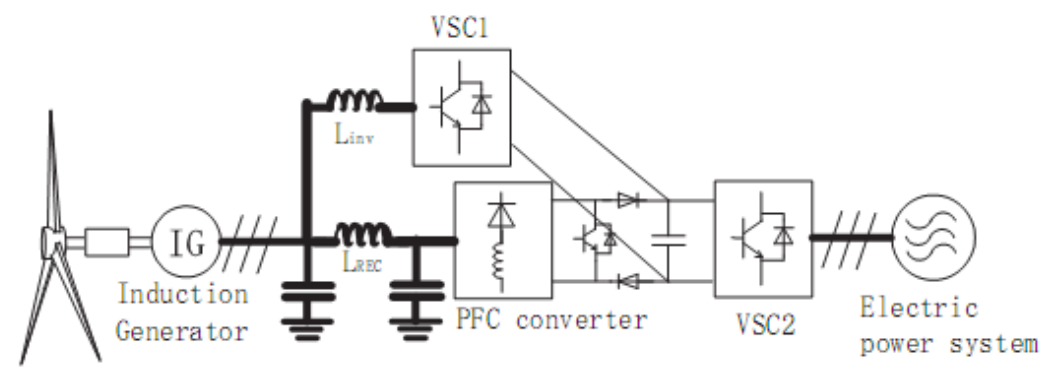

Fig 1.7 Proposed Wind Power Generation Systems with Induction Machine and Frequency Converter

In this system, the induction machine (IG), the voltage source converter (VSC) and the PFC converter (PFCC) are connected through the reactors $\mathrm{L}_{\mathrm{i}}, \mathrm{L}_{\mathrm{r}}$. The capacitors $\mathrm{Cc}$ are also connected for the reactive power compensation. The VSC can supply variable frequency ac voltage depending on the rotor speed which is changed by the wind power change. Therefore the induction generator can supply power at any rotor speed. For a cage-rotor induction machine, no power generation is possible in case of lower speed than synchronous speed. In this proposed system, low cost cage-rotor induction machine can be used with the voltage source converter for excitation instead of expensive permanent-magnet synchronous machine. This fact can realize the lower total system cost. The capacitors are also connected for the reactive power compensation.

\section{Phasor Analysis of Wind Energy Conversion System}

In proposed wind power generation system, the induction machine (IG), the voltage sourced converter (VSC) and the PFC converter (PFC conv.) are connected through the reactors $\mathrm{L}_{\mathrm{i}}, \mathrm{L}_{\mathrm{r}}$, as shown in Fig.7.1. The capacitors are also connected for the reactive power compensation. By neglecting the resistance of the reactor, the relations among the voltages and currents are expressed as follows Here $V_{g}, V_{i}, V_{r}, I_{g}, I_{i}, I_{r}$ are treated as the complex quantities. And $\mathrm{K}_{\mathrm{PFC}}$ is the AC/DC conversion factor of the diode rectifier and $\mathrm{d}_{\mathrm{F}}$ is the AC/DC duty factor of the boost chopper.

$$
\begin{gathered}
V_{g}=V_{i}-j w L_{i} I_{i} \\
V_{g}=V_{r}-j w L_{r} I_{r} \\
I_{g}+I_{i}+I_{r}=0 \\
V_{d c}=\frac{K_{p f c}}{1-d_{F}} V_{r}
\end{gathered}
$$




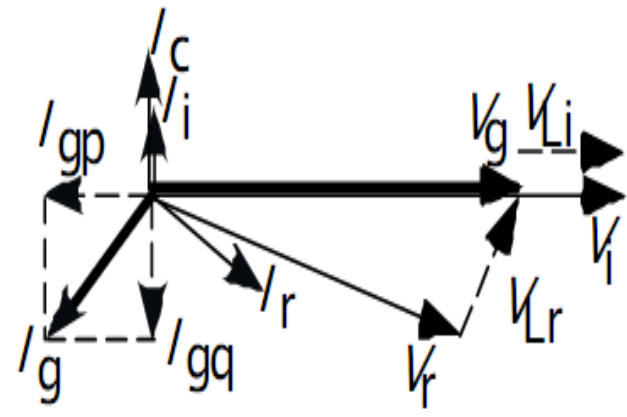

Fig 1.8 . Phasor Diagram of Voltages and Currents in Proposed System System

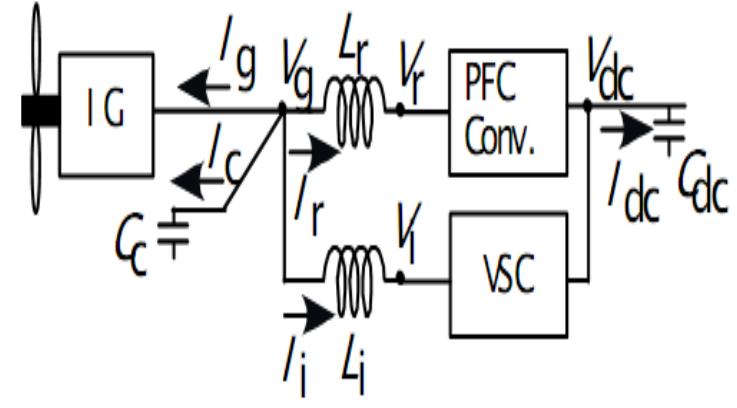

Fig 1.9 Voltages and Currents in Proposed

Controllable parameters are ac voltages of the inverter and the diode rectifier. Since the PFC converter works as the boost chopper, the duty factor $\mathrm{d}_{\mathrm{F}}$ determines the boost ratio between the input dc voltage and the output dc voltage. However, as the output dc voltage is constant, the input voltage changes. Therefore, the input ac voltage of the PFC converter decreases linearly to the duty factor $\mathrm{d}_{\mathrm{F}}$. As the result, against the generator output ac voltage $V_{g}$, the rectifier voltage $V_{r}$ is changed and the current $I_{r}$ is also changed. The reactor $L_{r}$ at the rectifier is relatively small and the decrease of the ac voltage $V_{r}$ is small, then the input power is increased by the increase of the current $\mathrm{I}_{\mathrm{r}}$. By using this process, the input active power to the PFC converter is controlled to be the same as the output active power from the induction generator, the active power from the inverter (VSC) can be kept to be zero.

\section{Simulation Circuit Of Proposed Wind Energy Conversion System}

The proposed system is implemented in the MATLAB/Simulink consists of Power factor correction converter (PFCC) is the combination of diode rectifier $+\mathrm{dc} / \mathrm{dc}$ chopper, Voltage source converter (VSC), induction generator. In this simulink circuit the voltage source converter injects the reactive power to the induction generator. The induction generator absorbs the reactive power and sends the real power to the PFC converter.

The inductor is connected in series to the diode for limiting the current distortion in the ac side of the PFC converter. The ac voltage is converted to dc voltage i.e is the rectified voltage. Then after there should be a $\mathrm{dc} / \mathrm{dc}$ chopper. However, as the output voltage changes depending on the rotating speed as the frequency, a boost chopper is installed in series to charge the dc capacitor at the higher voltage.

\section{MATLAB/Simulink Circuit for the Directly Grid Connected Induction Generator}

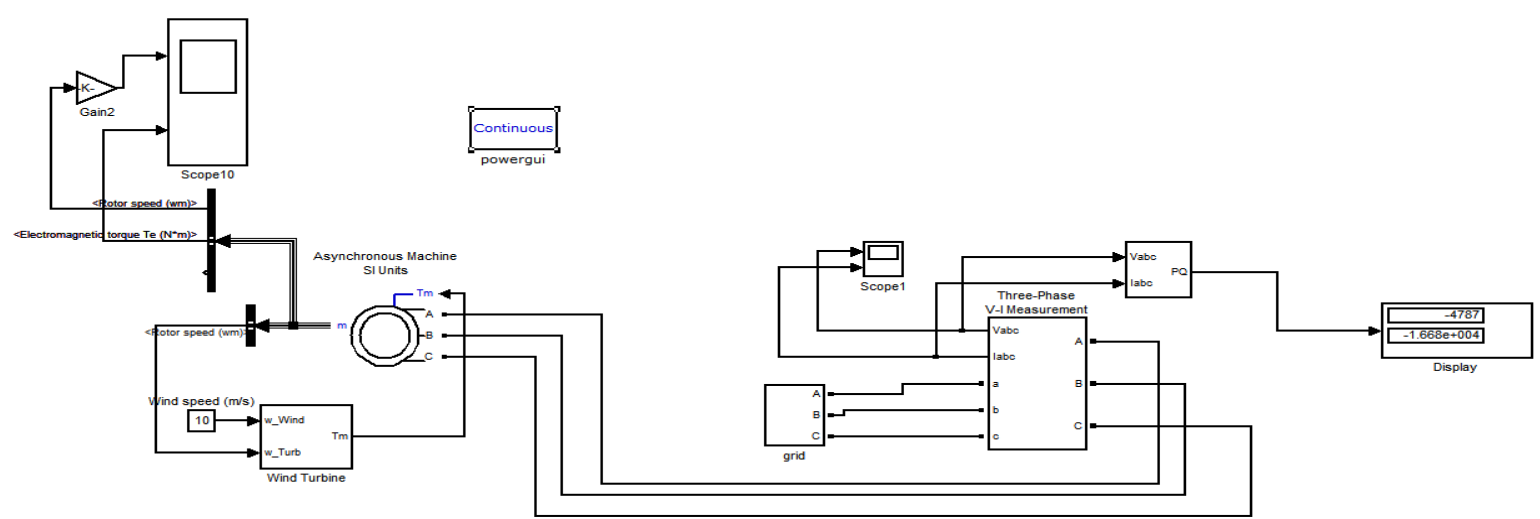

Fig 1.10 Grid Connected Induction Generator 


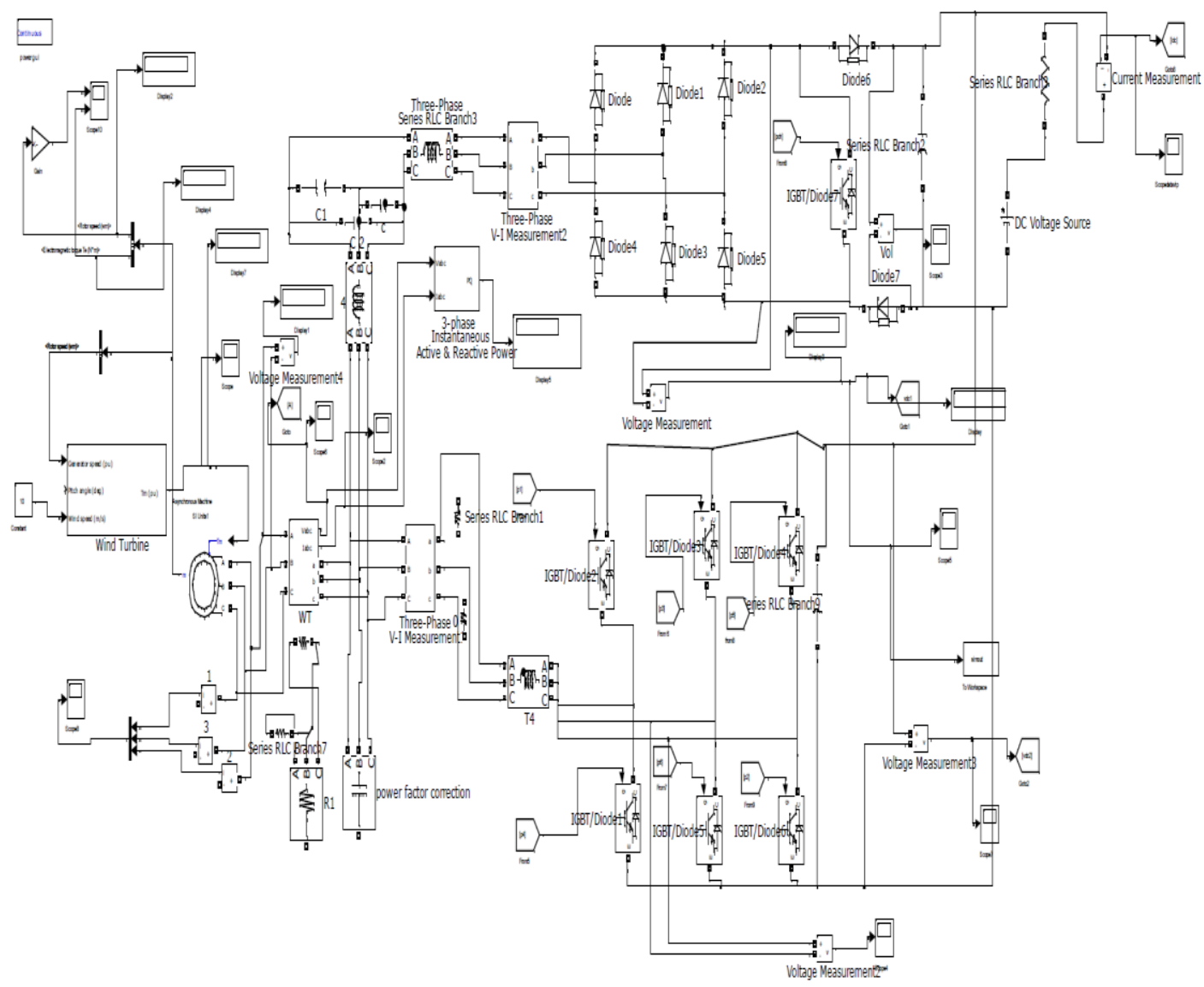

Fig 1.11 Schematic Diagram of the Simulation System

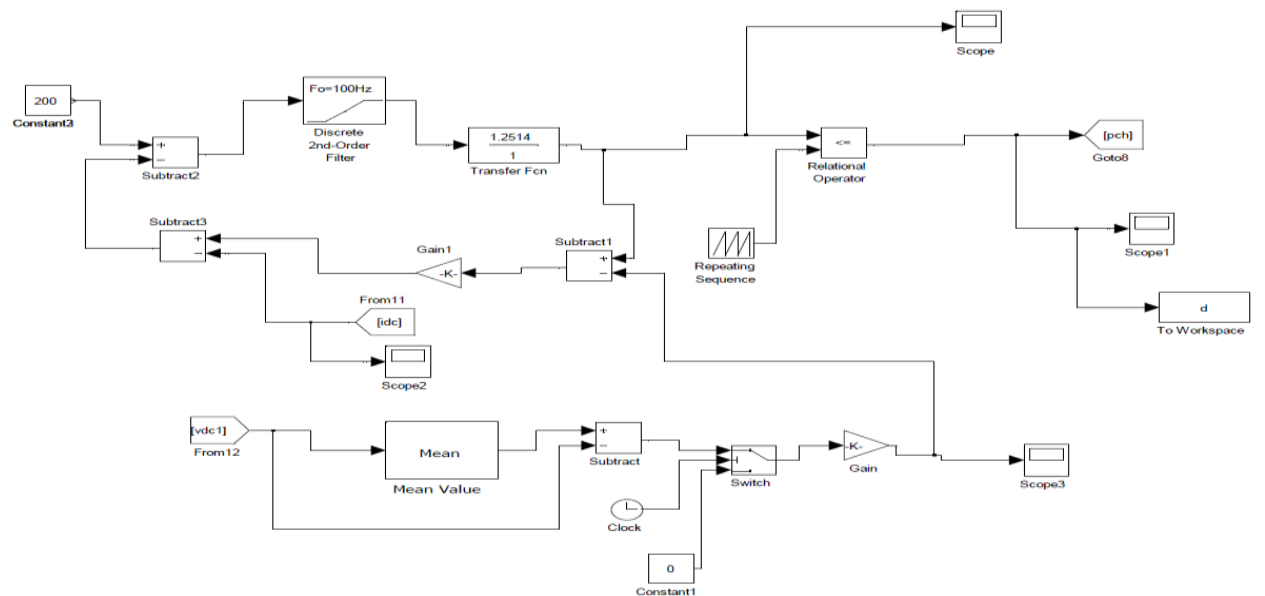

Fig 1.12 Control System of the Duty Factor Modulation Signal 


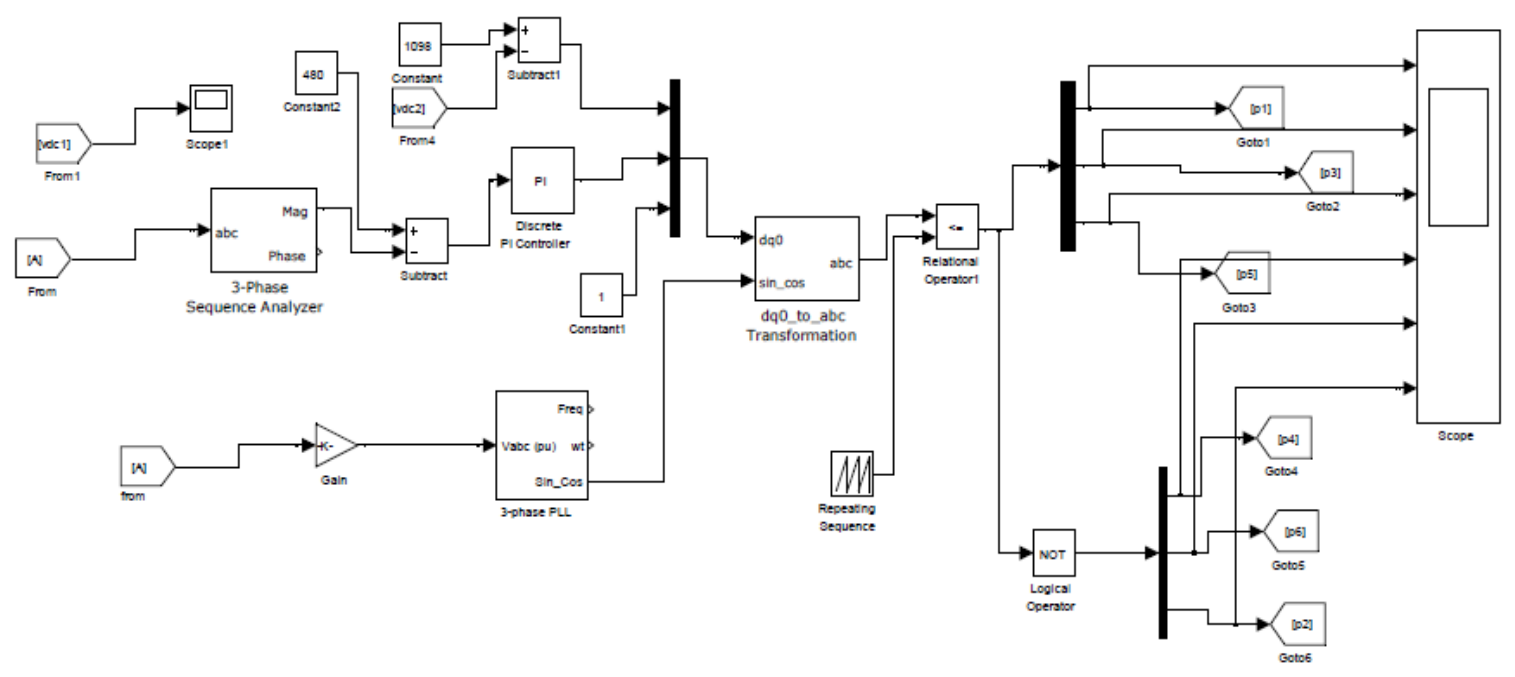

Fig 1.12 Generation of Pulses for the Switching of the Three Phase Voltage Source Converter

\section{I Simulation \& Result}

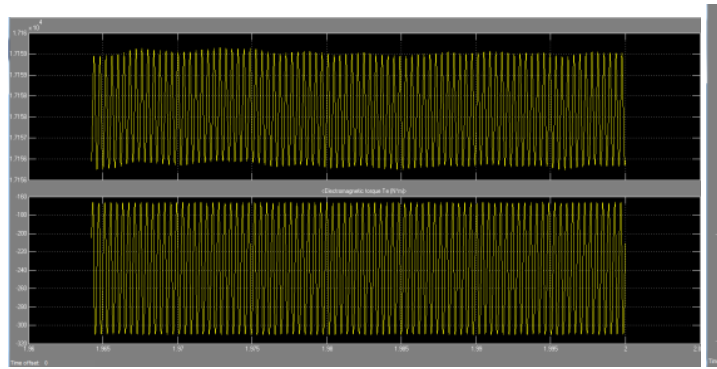

(a)

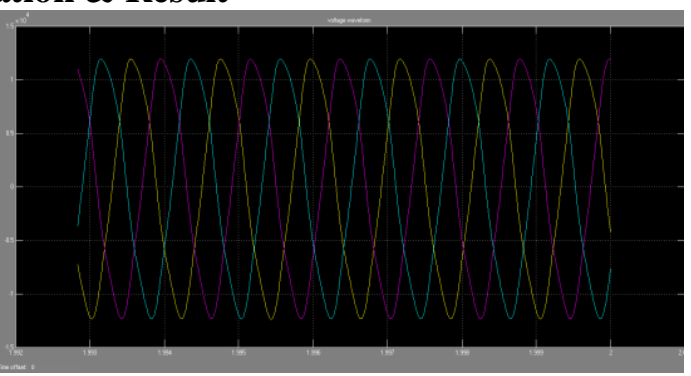

(b)

Fig 1.13 (a) Generation of Electromagnetic torque and rotor speed (b) Generation of three phase wave form
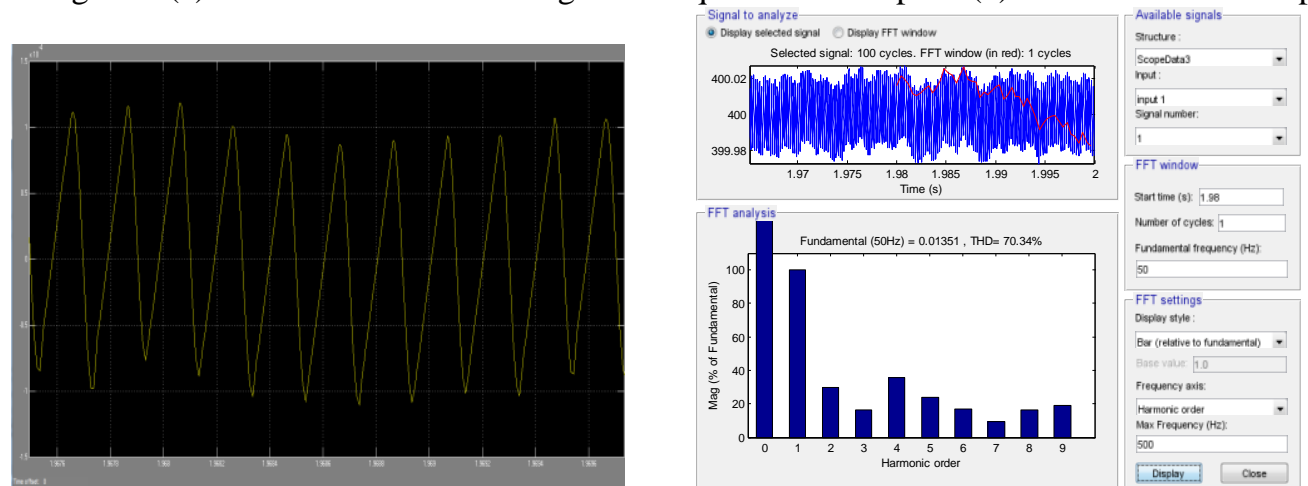

Fig 1.14 (a) Simulation of ac current without duty factor (b) FFT analysis without duty factor

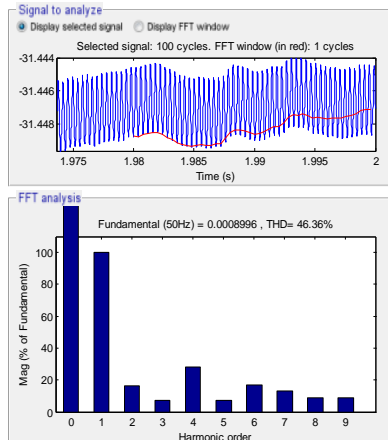

(a)

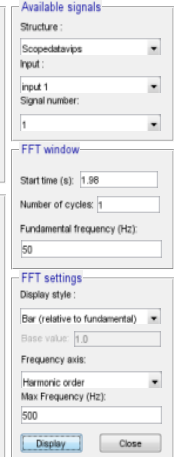

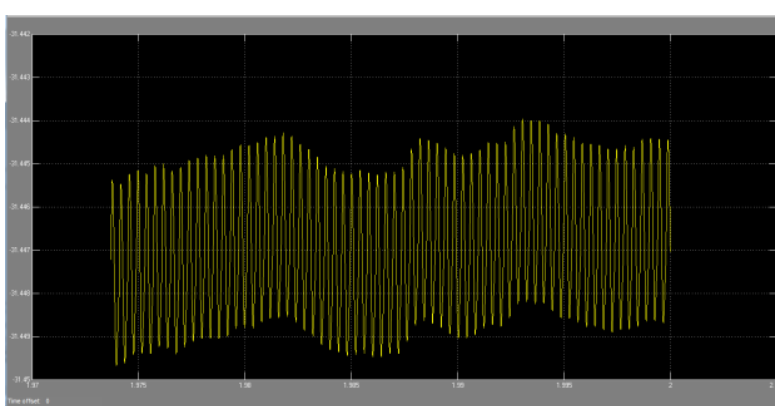

(b)

Fig No 1.15 (a) FFT analysis with duty factor (b) Simulation Wave form with duty factor 

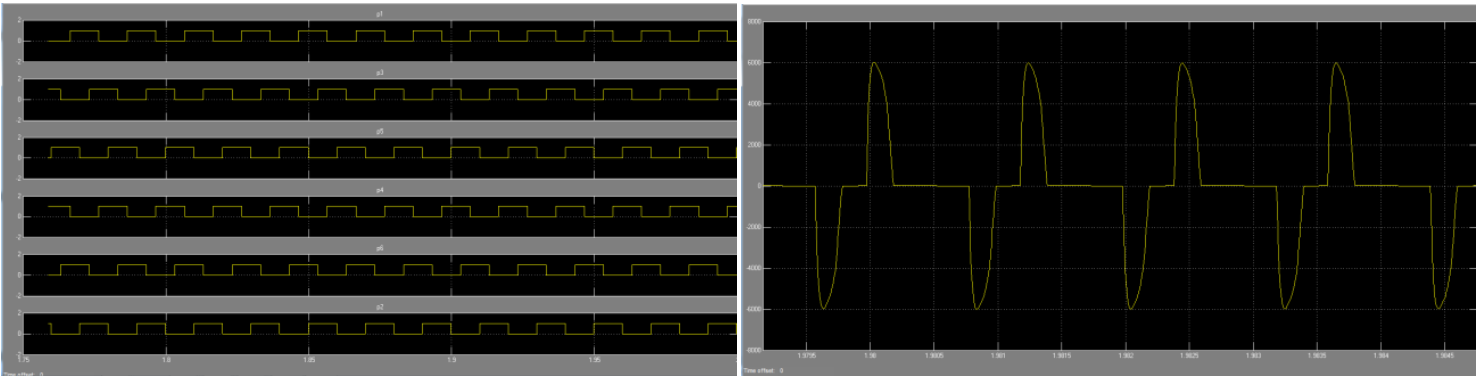

Fig 1.16 (a) Gate pulse voltage source converter (b) Ac voltage wave form across VSC

\section{Conclusion}

In this project, the proposed scheme, the diode rectifier is used to convert the real power from the induction generator to the intermediate dc voltage, while the reactive power necessary to excite the induction generator only is supplied from the voltage source converter (VSC). This means that the rating of the expensive VSC is minimized and total cost of the wind power generation system is decreased compared to the system with synchronous generator. It is verified the maximum current value is suppressed, by modulating the duty factor of the PFC converter, by the simulation

\section{References}

[1] Noriyuki Kimura , Tomoyuki Hamada, Makoto Sonoda , Toshimitsu Morizane Katsunori Taniguchi and Yasuyuki Nishida, “ Suppression of current peak of PFC converter connected to induction generator for wind power generation excited by voltage sources converter". IEEE 6th International Conference on power electronics and motion control, Page(s): 2269-2274, 17-20 May 2009.

[2] Bhim Singh, Shailendra Sharma ," Stand-Alone Wind Energy Conversion System withan Asynchronous Generator", Journal of Power Electronics, Vol. 10, No. 5,pp.538 547, September 2010

[3] Noriyuki Kimura, Toshimitsu Morizane, Katsunori Taniguchi, Tomoyuki Hamada, "Control of PFC Converter with Inverter Excited Induction Generator for Advanced Wind Power Generation System ", Proceedings of PESC'08 "The 39th IEEE Power Electronics Specialists Conference”, June15-19, 2008

[4] Noriyuki Kimura, Toshimitsu Morizane, Katsunori Taniguchi, Tomoyuki Hamada, "Wind Power Generation System with Induction Machine and Diode Rectifier ", EPE 2007, 12th European Conference on Power Electronics and Applications, No.0436, (2007-9)

[5] L. Leclercq, et.al, "Grid Connected or Islanded Operation of Variable Speed Wind Generators Associated with Flywheel Energy Storage Systems", EPE-PEMC-2004 Riga, Latvia. (European Association of Power Electronics and Applications - Power Electronics and Motion Control conference).

[6] Noriyuki Kimura, Toshimitsu Morizane, Katsunori Taniguchi, Tomoyuki Hamada, " Control of PFC Converter with Inverter Excited Induction Generator for Advanced Wind Power Generation System ", Proceedings of PESC'08 “The 39th IEEE Power Electronics Specialists Conference”, June15-19, 2008

[7] Hirachi, K. ; Res. \& Dev. Div., Yuasa Corp., Osaka, Japan ; Nishimura, K. ; Baba, N. ; Gamage, L. ,'Engine-driven generator interactive three-phase switched-mode PFC converter and its performance evaluations ",Industrial Electronics, 1997. ISIE '97., Proceedings of the IEEE International Symposium onpp 612 618 (Volume:2)

[8] Hansen, L.H. Madsen, P.H.; Blaabjerg, F.; Christensen, H.C.; Lindhard, U.; Eskildsen, K. "Generators and power electronics technology for wind turbines" IECON 2001, vol.3, pp: $2000-2005$

[9] Nicolás, C.V, Lafoz, M. And Iglesias, J. "Guidelines for the Design and Control of Electrical Generator Systems for new Grid connected Wind Turbine Generator." IECON 2002.

[10] Weigand, C.H., Lauw, H.K. and Marckx, D.A. "Variable-Speed Generation Subsystem Using the Doubly Fed Generator." NREL, April 1999. . 